\title{
Energy Efficiency in Brazil: Policies, Motivators, Barriers
}

\author{
T. T. Portela ${ }^{1}$, J. M. S Lafay ${ }^{1}$ \\ ${ }^{1}$ Post-graduate Program in Electrical Engineering \\ UTFPR, Federal Technological University of Parana \\ Campus of Pato Branco - Via do Conhecimento km 1, 85503-390, Patro Branco, PR (Brasil) \\ Phone: +55 463025 2240, e-mail: tarlis@ tarlis.com.br, jeanmarc@utfpr.edu.br
}

\begin{abstract}
This paper discusses energy efficiency in thermal processes of chicken slaughterhouses in Brazil, as they are large consumers of electricity and have few indicators to system monitoring. The article reviews energy efficiency in Brazil's industry, global policies, motivations and barriers to the adoption of an energy management system in the refrigeration circuit. The government lack of regulations towards the development of energy efficiency in the industry, also, that is not the concern of industries managers. That industry is losing competitiveness, as well, the country has an energy inefficient industry.
\end{abstract}

This work compares the production indicator commonly monitored by the chicken slaughterhouses: the Unit Cost which indicates that a slaughterhouse consumes $218.33 \%$ of energy in relation to another chicken slaughterhouse. It represents the energy consumed per kilogram of chicken processed, thus the second slaughterhouse uses more than the double of energy to produce the same amount of product. Thus, the disclosure of information for energy efficiency comparison may help the national industry to become more efficient and competitive.

\section{Key words}

Energy efficiency, indicators, energy policies, chicken slaughterhouses, barriers.

\section{Introduction}

Brazil is one of the major food producers in the world, because the national food industry is an important segment of economic activity in the country. According to [1], in recent years its turnover has grown, reaching approximately US $\$ 197.25$ billion in 2012, compared with revenues of 2011, which was US\$ 175 billion, increased by US\$ 22.2 billion, corresponding to $11.26 \%$ of gain. Brazil state of Parana led the poultry slaughter in 2012 with $29.7 \%$, followed by the states of Santa Catarina with 17.7\%; Rio Grande do Sul, 14.4\%; and Sao Paulo, 12.7\% [2]. As estimated by [3], 2012 data show that the United States lead the production of chicken meat with 19.79 million tonnes, followed by China with 18.51 million, 12.55 million in the European Union (EU) and Brazil with 11.3 million. Figure 1 illustrates the top producers of chicken meat in the world.
Brazil has overcame the production of poultry meat in the EU from 2008-2012, but its estimated to lose the third place to the EU again. Faced with growing production of chicken meat in Brazil, one of its consequences was the increase in electricity consumption, so the industrial sector was the Brazilian great energy consumer in 2012 with $41 \%$, followed by $26 \%$ households, $18 \%$ commercial and $15 \%$ others with a total consumption of $448 \mathrm{GWh}$ [4].

One of the key factors for chicken slaughterhouses to avoid waste, and minimize cost of electricity its the industrial refrigeration control. The cold chain comprises the whole process of storage, preservation, distribution, transportation and handling of products with controlled low temperature. Any failure in this chain can compromise product quality, by the speed of chemical reactions, biochemical and microbiological characteristics are directly related to temperature, influencing the health, nutritional quality and sensory quality of chilled products. Therefore, maintaining the cold chain intact, operating at proper temperatures from the producer to the final consumer, is essential [5]. The numbers involved in this segment are very high. The electric bill for large industries are an amount between US\$ 365.600,00 and US\$ $685.500,00$ per month, and the cooling sector corresponding to between $60-75 \%$ of the electric bill [4].

Thus, one of the characteristics faced by this industry is the high consumption of electrical energy that is concentrated in the cooling system and the engine compressors are the responsible of this consumption. Still, to reduce energy consumption the Brazilian Ministry of Mines and Energy, is developing energy efficiency programs that refer to various kinds of actions to culminate in reducing the energy needed for society's energy services demands in the form of light, heat, cold, activation, transport and use in processes. In short, the objective is to suit the needs of savings with lower primary energy use and therefore less impact on the nature [6]. 


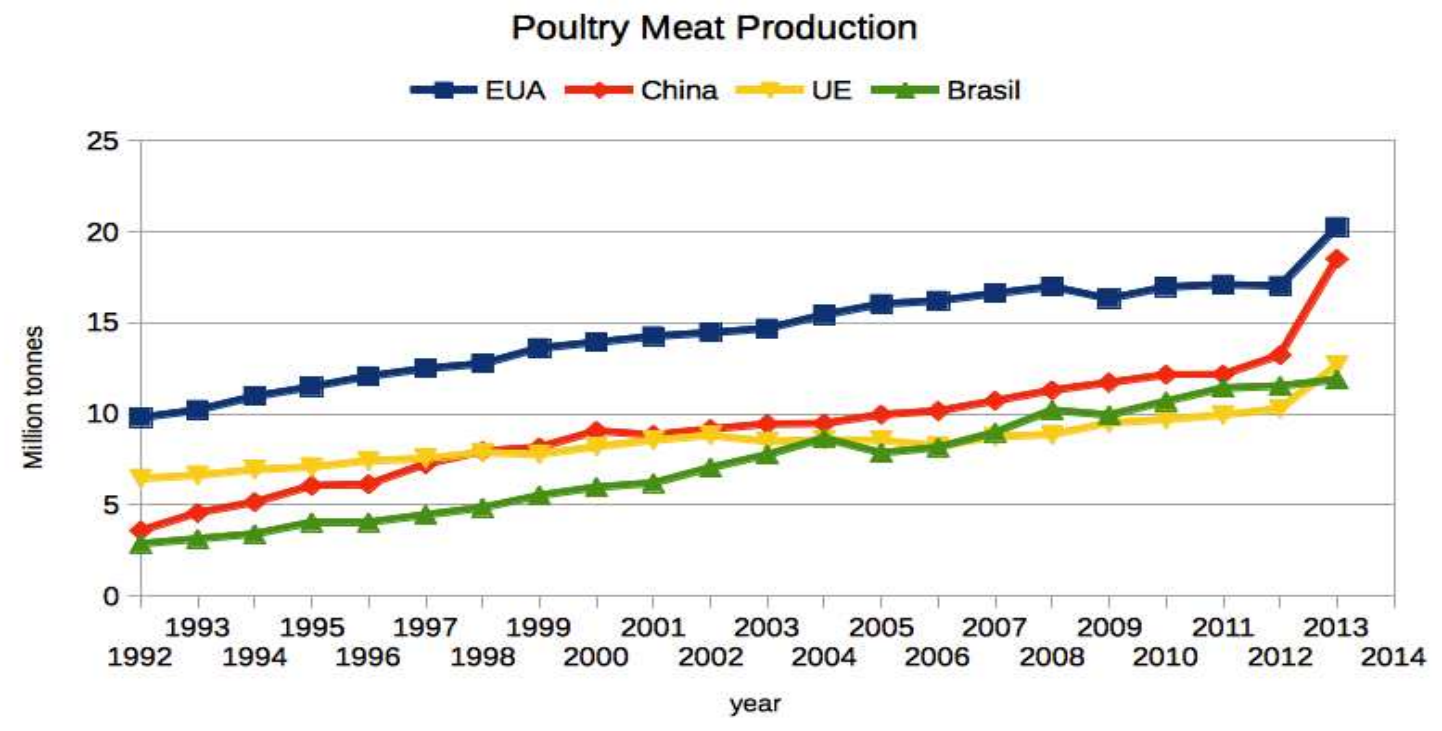

Fig. 1. Poultry production by country [3].

Projects are being carried out with the objective of promoting energy efficiency actions aiming at medium and large industries, through partnerships with industry federations of states, to train technicians and engineers who work in industry, education and services, aiming at the establishment of energy efficiency actions in industrial motor systems [7].

Energy efficiency (EE) has become a central topic in several countries and saving energy is on the companies and public institutions agenda. As the prices of electricity, oil and gas in Europe have continuously rising over the last 10 years, recently, there have been only policies influencing the implementation of industry energy efficiency [8].

In Brazil, the national energy efficiency plan aims to reduce energy consumption by $10 \%$ over the period 2010 2030 [1]. The country is among the 10 largest consumers of electricity in the world, although its share in total $(2.5 \%)$ is far from the United States (the largest consumer with $21 \%$ of the total). Although the rate of Brazilian industrial electrical energy is almost twice the value compared to the first placed, according to [9].

EE in Brazil industry has not developed despite government efforts. According to a survey of [10], in November 2011, demonstrates that the strategy of most importance to these companies is the "customer satisfaction". When asked where will go their next investments, $48 \%$ of entrepreneurs responded that they would invest in productivity.

A study of [11] comparing 16 countries around the world because they are large economies, showed that the country is on the penultimate rank of EE, ahead only of Mexico. This position is repeated in the evaluation of the industrial sector. The Brazil and Mexico are the only evaluated countries that has no voluntary agreements between government and organizations, or laws that require a professional dedicated to industrial energy efficiency programs, or even mandatory energy audits.

\section{Energy Efficiency}

EE can be controlled and systematized using a power management system based on ISO 50001 standard, which allows companies and other institutions to reach a sustainable energy reduction [8]. The use of indicators is a very important tool to highlight the system conditions, paths of their respective evolutions, for purposes of developing policies, they have the property of separating the important aspects of a wide range of information and thus can assist in decision-making processes. Therefore, indicators are needed in the process of monitoring, evaluation and diagnosis of the systems studied. The act of measurement is intrinsic to the human being, because of the interest in understand the environment around. In order to perform such task, important questions arise: what to measure, appropriate measuring instruments and their aim [12].

The energy management is a process of planning, improvement and verification according to a management model - to ISO 50001, the PDCA (Plan-Do-Check-Act). First, it makes a survey of the energy situation of the organization (called energy review) reporting the use and consumption of energy in the organization periodically, EE goals, objectives and actions are planned. For any energy efficiency plan is essential to identify process performance before and after improvement actions implementation, called Energy Base Line, and obtained by monitoring performance indicators.

Energy efficiency management is based in performance evaluation through indicators. Some indicators are monitored by slaughterhouses as the total consumption of electricity, cost per unit, generated financial value and annual savings. But they have few indicators to monitor the cooling system, since it consumes most of the power. 
Other important elements that must be checked are the factors that affect the efficiency of the cooling circuit and the technologies available for the equipments. Measuring the cooling system is possible to implement energy efficiency indicator called specific energy consumption represented by $\mathrm{kWh}$ per TR (tonnes of refrigeration), it determines the system efficiency (including management, maintenance and operation) in terms of income and monitors the system power consumption, its high rates points to excessive heat gain in the cooling system.

The energy management system (EMS) implementation in the refrigeration industry ends in creating a culture of efficiency and that can be the gateway to the development of efficiency across the organization. So, later, developing a culture of financial efficiency, production and other sectors of the institution, making it more competitive.

The monitoring of energy consumption is a key part to the implementation of a EMS and is only feasible when energy efficiency indicators are monitored, which would hardly be done manually. To identify causes of inefficiencies in the manufacturing process is not an easy task without the existence of sensors capable of obtaining information about energy use.

\section{Energy Efficiency and Voluntary Agreements}

Evidence of the last 3-4 decades of experience around the world indicate that EE programs are generally positive and bring multiple benefits to the government, consumers and environment. Such programs can: conserve natural resources; reduce pollution in the environment and also the energy demand of the industry; reduce the country's dependence on fossil fuels, thereby increasing its energy security; problems in infrastructure and impacts on temporary energy deficiencies; and improve industrial and commercial competitiveness by reducing operation costs [13].

The [14] and [15] estimate that energy efficiency policies can reduce annual emissions of $\mathrm{CO}_{2}$ in the world. According [13], IEA (International Energy Agency) developed a set of 25 recommendations that, if implemented, could reduce global emissions of $\mathrm{CO}_{2}$ to $20 \%$ per year until 2020. As suggest by [16]: only a coordinated policy, a hybrid of the renewable energy standard in which energy efficiency is also a source, the solution would be to expand EE and renewable energy investments.

In Brazil, several actions have been undertaken to promote EE in industry. Programs like: PROCEL with 650 participants industries by the end of 2008; PROESCO (Energy Efficiency Projects Support Program) with a funding coordinated by the National Bank for Economic and Social Development (BNDES); EE programs by the National Electric Energy Agency (ANEEL) and the CONPET by Petrobras [6].
Also [17] draws attention to the fact that in the literature, many tools are designed primarily to highlight issues that should be considered by companies, instead of performing an analysis of the factors that really influence business decisions in current market circumstances. And that the literature on sustainable business practices sometimes focuses on specific factors or classes of factors, rather than adopting a holistic approach in order to separate all possible factors. For example, researchers have repeatedly assumed an economic perspective, highlighting financial and organizational costs or benefits.

Various EE programs have been developed to reduce pollution and efficient use of energy. They are generally used in industry and offer motivators for developing the efficiency of these companies as tax reduction, ease environmental permits or other regulations. Some countries support the development of EE specialized centers for professional training and audits in industries.

Industry often receives reductions in tax rates on energy and carbon emissions if they follow certain measures of EE. However, the result of an EE program is uncertain: economic theory suggests that reducing the price of energy leads to an increase in consumption. Voluntary agreements (VA) policies have become increasingly common [18]. VA are benefits offered to institutions as an incentive to, for example, $\mathrm{EE}$ improvements, use of renewable and clean sources. Some have focused on industries only, while others allow associations and individual companies participate in programs which simplifies the implementation aspects [19]. A list of energy efficiency programs surveyed are listed in Table I.

There are several reasons why companies and public authorities agree to voluntary agreements and make certain commitments, summarizing:

1) Concessions as regulations and tariffs;

2) Easy access to environmental permits;

3) Financial support to take certain actions (as subsidies for energy audits and EE investments);

4) Reduction or exemption of taxes;

5) Providing information on EE technologies, government assistance and training in EE;

6) Public image of the participating institutions (environmental and social responsibility).

However, VA also use penalties or laws to discourage non-compliance. In cases of not compliance, the company may lose benefits or be penalized with fees and taxes. However, most of these programs seeks to promote EE through subsidies and no penalties. Moreover, the economic drivers have been the most common adherence of the participants to the VA [19].

EE programs in Brazil have no financial or fiscal incentives, being based on the dissemination of information to promote efficiency in industries. The Brazilian Labeling Program (PBE) aims to encourage the exchange of standard equipment with more efficient ones. 
Table I. - Motivations and mechanisms to discourage non-compliance.

\begin{tabular}{|c|c|c|c|}
\hline LOCAL & POLICIES & MOTIVATION & BARRIERS \\
\hline $\begin{array}{l}\text { Belgium- } \\
\text { Flanders }\end{array}$ & $\begin{array}{l}\text { Benchmarking covenant (BC), Auditing } \\
\text { Covenant (AC) }\end{array}$ & $\begin{array}{l}\text { Deferred legislation, tax } \\
\text { deductions for energy }\end{array}$ & \\
\hline $\begin{array}{l}\text { Belgium- } \\
\text { Walloon }\end{array}$ & & $\begin{array}{l}\text { Deferred legislation, tax } \\
\text { deductions for energy }\end{array}$ & \\
\hline Denmark & Voluntary agreements for energy efficiency & Tax discounts on $\mathrm{CO}_{2}$ & Discounts return \\
\hline Finland & $\begin{array}{l}\text { Energy Conservation Agreements (ECA), } \\
\text { Energy Efficiency Agreements on the } \\
\text { Improvement of Energy Efficiency in Industries, } \\
\text { Municipal Sector Agreement, Höylä III Energy } \\
\text { Efficiency Agreement }\end{array}$ & $\begin{array}{l}\text { Subsidies (energy audits and } \\
\text { implementing measures) }\end{array}$ & Subsides return \\
\hline Germany & $\begin{array}{l}\text { Joint Declaration of the German Industry on } \\
\text { Climate Protection }\end{array}$ & Tax discount on electricity & Discounts removal \\
\hline Estonia & Voluntary agreements to replace pollution taxes & $\begin{array}{l}\text { Replacement of pollution } \\
\text { charge }\end{array}$ & \\
\hline Ireland & Energy Agreements Program & EN16001 & $\begin{array}{l}\text { Tightening of } \\
\text { environmental permit } \\
\text { (LTA3) }\end{array}$ \\
\hline Netherlands & LTA3 e LEE & $\begin{array}{l}\text { Easier access to environmental } \\
\text { permits }\end{array}$ & Refund of tax credits \\
\hline Slovenia & Tax on $\mathrm{CO}_{2}$ and voluntary agreements & Tax discounts on $\mathrm{CO}_{2}$ & $\begin{array}{l}\text { Discontinuation of the } \\
\text { tax discount and } \\
\text { refund of tax credit }\end{array}$ \\
\hline Sweden & $\begin{array}{l}\text { Program for Energy Efficiency in Energy } \\
\text { Intensive Industries }\end{array}$ & Tax discount on electricity & $\begin{array}{l}\text { Discontinuation of tax } \\
\text { discount }\end{array}$ \\
\hline $\begin{array}{l}\text { United } \\
\text { Kingdom }\end{array}$ & $\begin{array}{l}\text { Climate Change Agreements (CCAs), EE } \\
\text { agreements with fuel carriers }\end{array}$ & $\begin{array}{l}\text { Discount climate change tax, } \\
\text { for CCAs }\end{array}$ & \\
\hline $\begin{array}{l}\text { United } \\
\text { States }\end{array}$ & Industrial Assessment Centres (IAC) & Training, industry audit & \\
\hline Brazil & $\begin{array}{l}\text { National Energy Efficiency Program (PROCEL), } \\
\text { the National Program for the Rational Use of Oil } \\
\text { Products and Natural Gas (CONPET), Brazilian } \\
\text { Labeling Program (PBE) }\end{array}$ & $\begin{array}{l}\text { Information popularization for } \\
\text { the development of EE, } \\
\text { labeling equipments efficiency }\end{array}$ & \\
\hline
\end{tabular}

And, the National Energy Efficiency Program (PROCEL) produces and disseminates information to improve $\mathrm{EE}$ in country.

Given Brazil's policy of information disclosure, results of EE programs report various projects developing improvements aimed at energy efficiency. They are, generally, replacements of less efficient equipment by other with greater performeance. Also, structural changes, equipment automation and building management processes on energy use.

Other studies published by CNI (National Industry Confederation) on EE solutions, concludes that $19 \%$ of the shares involved changing engines, $20 \%$ improvement in lighting systems and $8 \%$ improvement in compressed air systems [6]. Also, the IEA (International Energy Agency) suggests a checklist of energy efficiency [14].

\section{Motivations and Barriers}

A good part of the literature suggests that economic policies are the biggest motivators for institutions for adhesion to programs, moreover, that global businesses in general are sensitive to increasing need to raise and protect their reputation [17]. The larger the company, the more susceptible to public opinion. More and more large companies are required to act as industry leaders. The image of environmental responsibility while not a priority is, among others, a competitive advantage of industries. Nevertheless, to [19], an enormous potential for energy savings remains unusable by being trapped in industrial operations and management practices that are difficult to modify and optimize.

As highlighted by [19], some of the barriers to EE measures adoption are:
1) Distance core production;
2) Access to capital;
3) Economic and financial barriers;
4) Low priority investments in EE compared to others;
5) Initial capital needed;
6) Lack of time, or people;
7) Perceived risk of production interruption.

\section{Industry Unit Cost}

The most important indicator for chicken slaughterhouses production is the Unit Cost (UCe). It is related to the production and compares data on total chicken production 
over electricity consumption, en the amount of Watts hour consumed per kilogram of chicken meat processed.

Some studies have been done to verify the high electricity consumption in the chicken slaughterhouse industry. The first, conducted in the state of Paraná, in a industry named "A", which slaughter 180,000 chickens per day with a total power consumption of $38,650.36 \mathrm{kWh} / \mathrm{day}$. Its refrigeration sector consumes $32,084.38 \mathrm{kWh} /$ day, which represents $83 \%$ of all energy consumed and its UCe is $0.1517 \mathrm{kWh} / \mathrm{kg}$ of chicken [21].

According to [22], another chicken slaughterhouse ("B") in the same state processes an average of 2,779.9 tonnes of chicken meat (average of two years). Its average electricity consumption in 2011 and 2012 was approximately $622,429.9 \mathrm{kWh}$ and cooling sector consuming a total of $12,100,038 \mathrm{kWh}$, corresponding to $81 \%$ of the total consumption. And, ii has an UCe of $0.2239 \mathrm{kWh} / \mathrm{kg}$ of chicken processed.

Another study conducted by this paper to a slaughterhouse "C" in 2013, had an average production of over 3 million kilograms of chicken per month in that year and a monthly average consumption of $1,040,339.16 \mathrm{kWh}$. With on an UCe of 0.3312 , a performance way below the "A".

Comparing the refrigerator " $\mathrm{A}$ " and " $\mathrm{C}$ " can be noticed that the latter consumes $218.33 \%$ electrical energy to produce the same product. There's still the challenge to know what is the ideal value of UCe, since such data is not disclosed. In view of this, the refrigeration industry is unable to compare their performances, nor what actions should be taken to improve its performance.

\section{Conclusion}

The studies described do not address the energy consumption of the refrigeration sector cooling capacity — the major consumer — and it is not possible to identify the degree of system inefficiency or its cause. Publications on the results of these indicators are scarce on the national level and industries do not disclose this data for their protection from competitors. This way, the government does not have access to this information to make comparisons between data from electricity consumption and determine an ideal value of an efficient UCe. If such data is transmitted and disseminated, industries could obtain performance indicators with more efficient levels, reducing electricity consumption and make their processes more competitive with each other and with the international market.

\section{Acknowledgement}

The authors acknowledge FINEP, CAPES, SETI, CNPq, Fundação Araucária and UTFPR - Campus Pato Branco, for scholarships and funding.

\section{References}

[1] ABIA, Brazilian Food Industry Association, " 6 ' Congresso Internacional de Food Service”, 2013.

[2] UBABEF, Brazilian Poultry Union. "Últimos números da avicultura", 2013.

[3] FAO, Food and Agriculture Organization of the United Nations. "Food Outlook, Biannual Report on Global Food Markets", Rome - Italy, 1999-2013.

[4] G. Bourroul, "The price of cooling", in Journal of the National Meat, 2006. Vol. 357, pp. 36-44.

[5] Evaluation of temperatures in a refrigerated container for chilled and frozen food transport. Ciência e Tecnologia de Alimentos, Vol. 30, p.158, 2010.

[6] MME, Ministry of Mining and Energy, "PNEF, National Plan for Energy Efficiency", 2011.

[7] A.H.M. Santos, et al., "Conservação de energia: eficiência energética de equipamentos e insltalações”. 3. ed. Itajubá: FUPAI, 2006.

[8] T. Fiedler, P. Mircea. "Energy management systems according to the ISO 50001 standard - Challenges and benefits", Applied and Theoretical Electricity (ICATE), 2012 International Conference on , vol., no., pp.1,4, 25-27, 2012.

[9] EPE, Energy Planning Company, "Electricity Statistical Yearbook of 2013. Rio de Janeiro 2013.

[10] FIEP, State of Paraná Industries Federation, "XVI Industrial Survey," 2011.

[11] R. Young, S. Hayes, M. Kelly, S. Vaidyanathan, S. Kwatra, R. Cluett, G. Herndon, "The 2014 International Energy Efficiency Scorecard", 2014.

[12] E. Geisler, "The metric of science and technology". USA: Green Wood Publishing Group. 2000.

[13] A. Sarkar, J. Singh, "Financing energy efficiency in developing countries - lessons learned and remaining challenges", Energy Policy 2010, Vol. 38, pp. 5560-5571.

[14] IEA, International Energy Agency, "World energy outlook 2011 ", Paris 2011.

[15] L. M. Abadie, R. A. Ortiz, I. Galarraga, "Determinants of energy efficiency investments in the US", Energy Policy 2012, Vol. 45, pp. 551-566.

[16] P. Cappers, C. Goldman, "Financial impact of energy efficiency under a federal combined efficiency and renewable electricity standard: Case study of a Kansas superutility", Energy Policy 2010, Vol. 38, pp. 3998-4010.

[17] G. Pellegrini-Masini, C. Leishman, "The role of corporate reputation and employees values in the uptake of energy efficiency in office buildings", Energy Policy 2011, Vol. 39, pp. 5409-5419.

[18] E. Henriksson, P. Söderholm, L. Wårell, "Industrial electricity demand and energy efficiency policy: The role of price changes and private R\&D in the Swedish pulp and paper industry", Energy Policy 2012, Vol. 47, pp. 437-446.

[19] S. Rezessy, P. Bertoldi, "Voluntary agreements in the field of energy efficiency and emission reduction: Review and analysis of experiences in the European Union", Energy Policy 2011, Vol. 39, pp. 7121-7129.

[20] T. Fleiter, S. Hirzel, E. Worrell, "The characteristics of energy-efficiency measures - a neglected dimension", Energy Policy 2012, Vol. 51, pp. 502-513.

[21] A. Zanin, S. N. M. Souza, E. V. Kolling, A. Sordi, "Perfil do Consumo de Energia Elétrica no Abate de Frangos de Corte - Estudo de Caso", 40 Encontro Anual de Energia do Meio Rural, Cascavel, 2002.

[22] J.F. Frozza, "Eficiência energética em indústria frigorífica; desafios de implantação", Dissertation, Universidade Tecnológica Federal do Paraná, Programa de Pós-Graduação em Engenharia Elétrica, Pato Branco, 2013. 